\title{
Brief neonatal nutritional supplementation has sex-specific effects on glucose tolerance and insulin regulating genes in juvenile lambs
}

\author{
Anne L. Jaquiery ${ }^{1,2,3}$, Sharon S. Park ${ }^{1}$, Hui Hui Phua', Mary J. Berry ${ }^{1}$, Daphne Meijler', Jane E. Harding ${ }^{1}$, Mark H. Oliver ${ }^{1,2}$ and \\ Frank H. Bloomfield ${ }^{1,2,3}$
}

\begin{abstract}
BACKGROUND: The nutritional plane and composition during fetal life can impact upon growth and epigenetic regulation of genes affecting pancreatic $\beta$-cell development and function. However, it is not clear whether $\beta$-cell development can be altered by nutritional factors or growth rate after birth. We therefore investigated the effect of neonatal nutritional supplements on growth, glucose tolerance, and pancreatic development in lambs.
\end{abstract}

METHODS: Newborn lambs were randomized to daily nutritional supplements, calculated to increase macronutrient intake to a similar degree as human breast milk fortifier, or an equivalent volume of water, for 2 wk while continuing to suckle ewe milk. Intravenous glucose tolerance test (IVGTT) was performed at 4 mo of age, and pancreata collected for molecular analysis.

RESULTS: Supplemented lambs had slower weight gain than controls. In supplemented lambs, insulin response to IVGTT was increased in males but decreased in females, compared to same sex controls, and was unrelated to growth rate. mRNA expression of key genes in $\beta$-cell development showed sexually dimorphic effects. Epigenetic change occurred in the promotor region of PDX1 gene with decreased suppression and increased activation marks in supplemented lambs of both sexes.

CONCLUSION: Nutritional interventions in early life have long-term, sex-specific effects on pancreatic function.

$\mathbf{N}$ utrition during intrauterine life is the main determinant of fetal growth (1), a key factor in pancreatic development $(2,3)$ and a powerful modulator of epigenetic regulation of genes affecting insulin synthesis and secretion (4). After birth, the "gold standard" of nutrition in healthy term infants is breast milk. However, some infants receive formula feeds, which have a greater macronutrient content than breast milk (5), and growth-restricted babies are often given supplemental calories, macronutrients, or micronutrients to meet their nutritional needs. This frequently is achieved by the use of breast milk fortifier, which increases carbohydrate and protein content per unit volume when added to breast milk, in conjunction with specific vitamin and mineral supplements (6). Although there are some reports of the effects of nutritional supplementation on growth (7) and cognitive development (8), their effects on later metabolic function are unknown.

Studies of metabolic dysfunction after postnatal nutritional interventions have often focused on associations between the rate of neonatal weight gain and later outcomes such as obesity and insulin resistance $(9,10)$. For example, in studies of formula feeding vs. breast feeding, or comparisons between high and low protein containing infant formulas, rates of obesity and altered insulin dynamics have largely been attributed to a difference in growth rates between groups, assuming overnutrition, accelerated growth rates, and change in body composition to be causative factors (11-13). One difficulty with this assumption, however, is the poor correlation between energy intake and growth rate in the immediate postnatal period, particularly after intrauterine insult (14). It may be that intrauterine factors influence both early growth rate and later metabolism more strongly than postnatal caloric intake, and that dietary composition per se influences the development of physiological pathways and organ development independently of early growth rate.

In animal experiments, both the quality and quantity of the postnatal diet have been shown to alter pancreatic development. In rats, a low protein, isocaloric diet post weaning was associated with lower serum concentrations of insulin after feeding and altered expression of several pancreatic islet cell genes that encode for proteins related to insulin synthesis and secretion (15). Altering the quantity of milk intake during the suckling period by random assignment of male rat pups to small, medium (control) or large litter size resulted in an early and sustained defect in glucose responsiveness of pancreatic insulin secretion in both the large and small litter groups compared with controls, and differential expression of several islet cell genes through to adulthood (16). However, rats are altricial species, developmentally immature at birth compared

'The Liggins Institute, University of Auckland, Auckland, New Zealand; ${ }^{2}$ Gravida, Centre for Growth and Development, University of Auckland, Auckland, New Zealand; ${ }^{3}$ Department of Paediatrics: Child and Youth Health, University of Auckland, Auckland, New Zealand. Correspondence: Anne L. Jaquiery (a.jaquiery@auckland.ac.nz) Received 26 March 2016; accepted 4 July 2016; advance online publication 28 September 2016. doi:10.1038/pr.2016.168 
with humans and most other mammals, so that it is not possible to relate the developmental effects of postnatal nutrition in rats to humans.

To further understand how manipulations of dietary quality and quantity in early postnatal life might impact on pancreatic development and function without the added confounders of nutritional compromise before or after birth, we investigated, in healthy term lambs, the effects of nutritional supplements based on human breast milk fortifier, adjusted for ewe milk composition, given for the first 2 wk after birth, on growth, milk intake, glucose tolerance, and key genes in pancreatic $\beta$-cell development and insulin synthesis.

\section{RESULTS}

\section{Milk Intake and Growth}

Forty-two singleton lambs commenced the study; 20 were supplemented (S) and 22 served as controls (C) (Table 1). During the 2-wk period of supplementation (the first $2 \mathrm{wk}$ after birth), growth velocity was lower in $\mathrm{S}$ than $\mathrm{C}$ lambs $(P=0.006)$. In the subset of 17 lambs ( $8 \mathrm{C}$ and $9 \mathrm{~S}$ ) that underwent measurement of milk intake during the second week after birth, there was a trend toward S lambs having lesser volume, but not caloric, intake than $C$, and males a lesser intake than females (group effect $P=0.06$, sex effect $P=0.06$, no group $\times$ sex interaction) (Table 1). Protein intake was increased in supplemented lambs of both sexes, despite the trend toward lesser volume (Table 1). There was no difference in weight between $S$ and $C$ lambs, and males were heavier than females at each time point.

\section{Glucose Tolerance at 4 mo of Age}

Intravenous glucose tolerance tests (IVGTT) were completed successfully on 39 of the 42 lambs at 4 mo of age (juvenile, just before puberty).

Glucose area under the curve to 60 min $\left(\mathrm{AUC}_{60}\right)$ was less in $\mathrm{S}$ male lambs than all other groups (group effect $P=0.03$, group $\times \operatorname{sex} P=0.04$ ) (Table 2). Glucose $\mathrm{AUC}_{180}$ was also lesser in $\mathrm{S}$ lambs (group effect $P=0.04$ ).

Table 1. Growth and milk intake in control and supplemented lambs

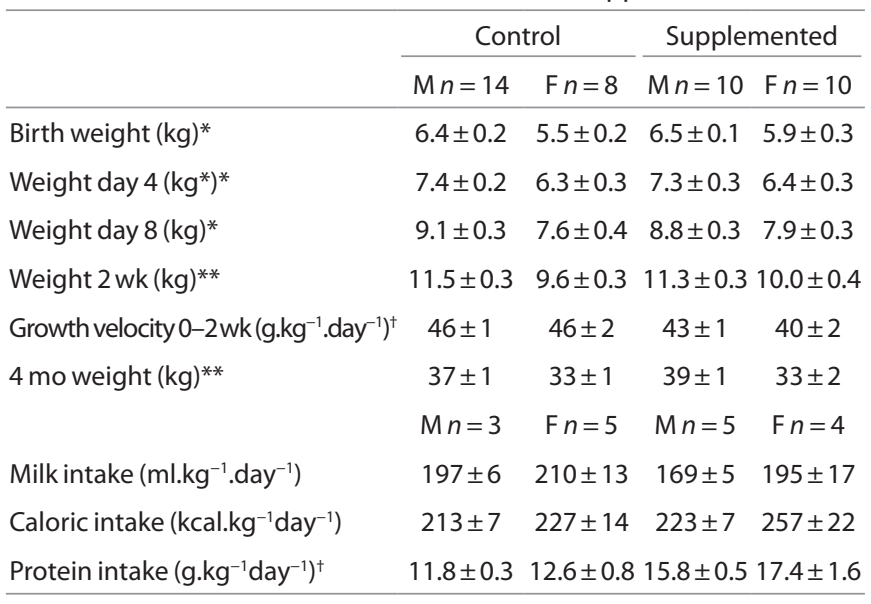

Values are mean \pm SEM. Milk intake was measured during the second week after birth. ${ }^{*} P<0.01,{ }^{* *} P<0.001$ for difference between males $(\mathrm{M})$ and females $(\mathrm{F}){ }^{+} P<0.01$ for difference between control and supplement groups.
Insulin $\mathrm{AUC}_{60}$ was greater in $\mathrm{S}$ males but lesser in $\mathrm{S}$ females compared to $C$ lambs (Group $\times \operatorname{sex} P=0.03$, Figure 1). Insulin $\mathrm{AUC}_{180}$ also was least in $\mathrm{S}$ females (Table 2). Similarly, when glucose and insulin $\mathrm{AUC}_{60}$ were expressed as a ratio, values were least in $\mathrm{S}$ males and greatest in $\mathrm{S}$ females (group $\times \operatorname{sex} P$ $=0.04)$ (Table 2).

Neither glucose nor insulin AUC at any time point were related to lamb growth velocity in the first $2 \mathrm{wk}$ of life (data not shown).

\section{Postmortem Findings}

Twenty-one lambs (13 male, $\mathrm{C} n=6, \mathrm{~S} n=7 ; 8$ female, $\mathrm{C} n$ $=3$, S $n=5$ ) underwent postmortem after the glucose tolerance test at $4 \mathrm{mo}$ of age. Males were heavier than females ( $28 \pm 1$ vs. $24 \pm 1 \mathrm{~kg}, P=0.03$ ) and had greater lung and kidney weights when expressed as \% body weight (data not shown). Supplementation did not alter organ weights relative to body weight.

\section{mRNA Expression in the Pancreas}

Supplementation decreased PDX1 (pancreatic and duodenal homeobox 1), SLC2A2 (glucose transporter 2) and IGF2 (insulin-like growth factor 2) mRNA levels in $\mathrm{S}$ males, but not females, compared with same sex controls (all $P<0.01$ ) (Figure 2).

Table 2. Intravenous glucose tolerance tests at age 4 mo in control and supplemented groups

\begin{tabular}{|c|c|c|c|c|}
\hline & \multicolumn{2}{|c|}{ Control } & \multicolumn{2}{|c|}{ Supplement } \\
\hline & $M n=12$ & $\mathrm{~F} n=8$ & $M n=9$ & $\mathrm{~F} n=10$ \\
\hline Baseline glucose $\left(\mathrm{mmol} . \mathrm{I}^{-1}\right)$ & $3.5 \pm 0.1^{b^{*}}$ & $3.8 \pm 0.1^{\mathrm{a}}$ & $3.9 \pm 0.1^{\mathrm{a}}$ & $3.8 \pm 0.1^{\mathrm{a}}$ \\
\hline Glucose $A \cup C_{60}\left(\right.$ mmol.min. $\left.^{-1}\right)$ & $619 \pm 17^{a}$ & $582 \pm 16^{a}$ & $511 \pm 13^{b *}$ & $580 \pm 32^{\mathrm{a}}$ \\
\hline Glucose AUC $_{180}\left(\mathrm{mmol} \cdot \mathrm{min} . \mathrm{l}^{-1}\right)^{\dagger}$ & $964 \pm 52$ & $889 \pm 54$ & $770 \pm 74$ & $834 \pm 65$ \\
\hline Baseline insulin (ng.min.mll ${ }^{-1}$ ) & $0.07 \pm 0.02$ & $0.12 \pm 0.02$ & $0.07 \pm 0.02$ & $0.06 \pm 0.02$ \\
\hline Insulin $\mathrm{AUC}_{60}$ (ng.min. $\left.\mathrm{ml}^{-1}\right)^{\ddagger}$ & $68 \pm 7$ & $90 \pm 16$ & $99 \pm 23$ & $56 \pm 8$ \\
\hline Insulin AUC ${ }_{180}$ (ng.min.ml-1 $\left.{ }^{-1}\right)$ & $131 \pm 11$ & $146 \pm 22$ & $140 \pm 23$ & $103 \pm 9^{*}$ \\
\hline Glucose AUC $_{60}$ :Insulin AUC ${ }_{60}{ }^{\neq}$ & $10.4 \pm 1.1$ & $7.7 \pm 1.1$ & $8.1 \pm 1.9$ & $12.2 \pm 1.7$ \\
\hline
\end{tabular}

${ }^{*} P<0.05$ for difference from subgroups denoted by a different letter. ${ }^{\dagger} P<0.05$ for group effect. ${ }^{*} P<0.05$ for Group $\times$ sex interaction.

AUC, area under the curve.

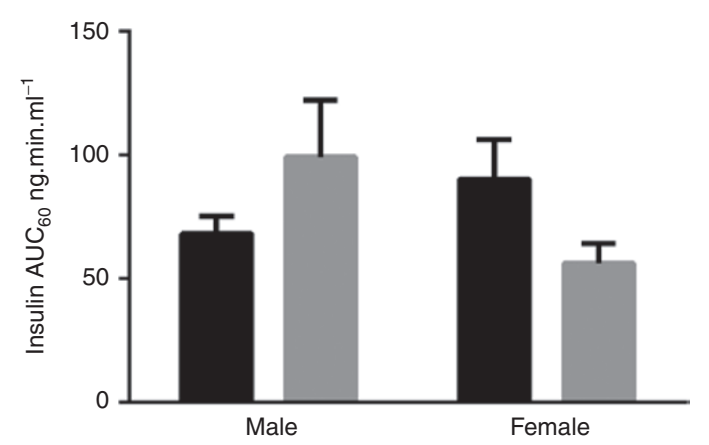

Figure 1. Insulin AUC60 in supplemented and control lambs. Control group represented by dark bars, supplemented group represented by light bars. M, male; F, female; C, control; S, supplemented; group $\times$ sex interaction $P=0.03$ 


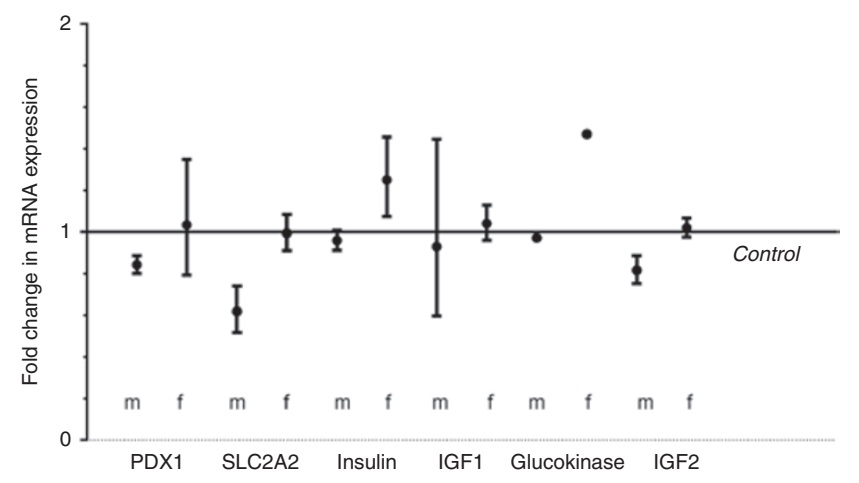

Figure 2. mRNA expression in the pancreas. Values are expressed as fold change in mRNA levels in supplemented males $(M)$ and females $(F)$ relative to the same sex control group (represented by the horizontal line) and normalized to the Bestkeeper index with $95 \%$ confidence intervals. Thus, mRNA levels are significantly different from same-sex controls at the $5 \%$ level if the $95 \%$ confidence intervals do not cross 1.

mRNA levels of INSULIN and GLUCOKINASE were increased in $S$ females, but not males, compared with same sex controls ( $P<0.01$ for both).

Supplementation did not alter mRNA levels of IGF1.

\section{Epigenetic Marks in the Promotor Region of the PDX1 Gene}

The promotor region of the PDX1 gene was studied to clarify whether the observed changes in mRNA levels in response to supplementation (found on real-time PCR analysis) were regulated by a change in epigenetic status of $P D X 1$. In the promotor region of the $P D X 1$ gene, DNA methylation, a repressor mark, was decreased in S animals of both sexes compared with C (\% enrichment methylated genomic DNA:total genomic DNA Control M 11.02 \pm 1.2 , F 9.16 \pm 2.2 ; Supplemented M 7.83 \pm 1.2 , F 5.36 \pm 1.02 ; group effect $P=0.02$ ). Enrichment of $H 3 \mathrm{~K} 27 \mathrm{me} 3$, another repressor mark, was greatest in $\mathrm{C}$ females (sex effect $P=0.03$, sex $\times$ group interaction $P=0.04$ ) (Figure 3a). H3K9 acetylation, an activating mark, showed greatest \% fold enrichment in $\mathrm{S}$ females (sex effect $P=0.01$ ) (Figure $3 \mathrm{~b}$ ), while another activating mark, H3K4me3 acetylation, was not different between groups or sexes (Figure 3c).

\section{DISCUSSION}

Brief postnatal nutritional supplementation of healthy term lambs resulted in epigenetic change in pancreatic $\beta$ cells, and sex specific alteration in mRNA expression of genes related to $\beta$ cell development and function. This confirms that early postnatal nutrition is a powerful modulator of epigenetic change, and may alter organ development in ways that affect long-term metabolic outcomes.

The nutritional intervention in this study was designed to result in a percentage increase in macronutrients equivalent to that seen when human milk fortifier is added to expressed breast milk, adjusted for the differing compositions of human and ewe milk. There are robust data associating intrauterine nutrition with pancreatic development and later function. In growth restricted human fetuses, pancreatic $\beta$ cell fraction, islet vascularization, and in vivo $\beta$ cell responsiveness have a

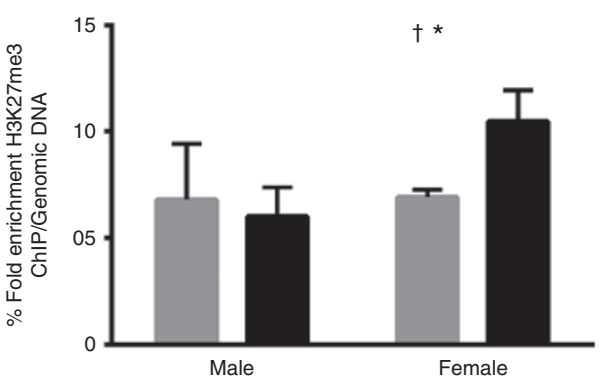

b

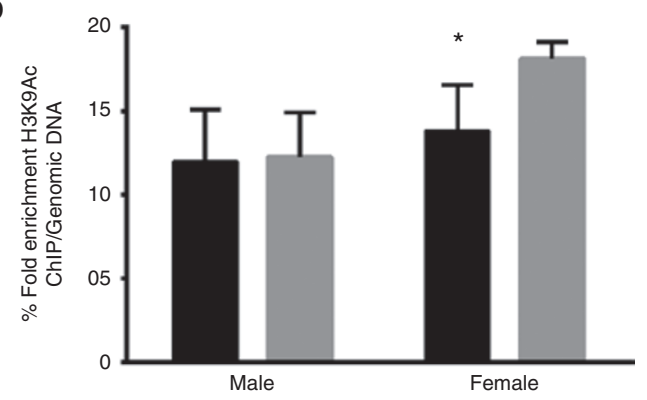

C

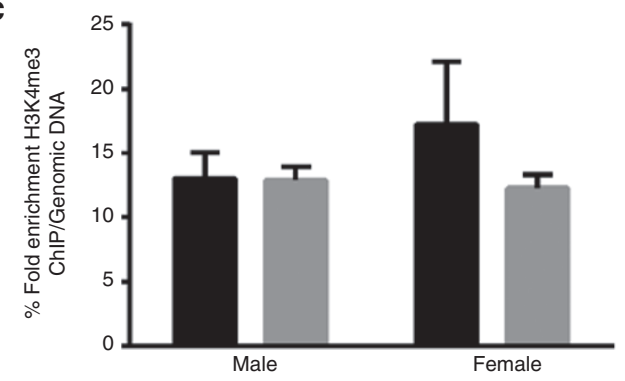

Figure 3. \% fold enrichment of (a) H3K27me3, (b) H3K9Ac, and (c) H3K4me3 ChIP/genomic DNA. Control group C represented by dark bars, supplemented group $S$ represented by light bars. * represents sex effect $P<0.05 ;{ }^{+}$represents sex by group interaction $P<0.05$.

been shown to be reduced (17). Studies in rodents have shown a clear association between fetal growth restriction and $\beta$ cell dysfunction, dependent on the type, timing, and duration of the fetal insult (15-18). In particular, both maternal caloric restriction and a maternal low protein, isocaloric diet resulted in decreased $\beta$ cell mass in the offspring, but via different mechanisms. In fetuses of dams fed a low-energy diet, decreased $\beta$ cell mass was due to reduced neogenesis indicated by fewer cells positive for Ngn3 and Pdx-1 (transcription factors that are involved in the $\beta$ cell lineage), whereas the low-protein diet reduced offspring $\beta$ cell mass by impairing islet vascularization and $\beta$ cell proliferation (19). Beta cell mass was also reduced in fetal sheep that were growth restricted after either placental restriction via removal of placental implantation sites (20) or maternal exposure to a warm environment (21). However, it is also important to note that nutritional interventions in pregnant ewes can also result in altered glucose tolerance in the offspring independent of changes in birth weight (22).

There are fewer reports relating postnatal nutrition alone to metabolic outcomes. Increasing postnatal caloric intake in rats reduced glucose-stimulated insulin secretion after weaning and 
resulted in differential expression of a range of islet cell genes involved in insulin regulation, including reduced mRNA levels of the insulin gene (16). Altering nutritional quality by giving an isocaloric, high carbohydrate milk formula to rats in the neonatal period resulted in hyperinsulinemia and increased glucokinase and Slc2a2 protein content, which persisted into adulthood (23). However, the developmental immaturity of rats at birth makes meaningful comparisons with humans and other mammals difficult. In sheep, which have an intrauterine developmental trajectory more similar to humans, pancreatic development and remodeling occur in late gestation and continue into the postnatal period; hence, we hypothesized that neonatal nutritional manipulation in lambs would result in epigenetic change and mRNA expression of genes involved in insulin synthesis and secretion. There are a number of potential target genes in which epigenetic change could result in altered glucose-insulin axis function. The transcription factor PDX1 is one of the most important in the development of the pancreas (24). Postnatally, $P D X 1$ is selectively expressed in the $\beta$ cells and plays a key role in $\beta$ cell growth and development. Insulin-like growth factors (IGF)-1 and -2 also influence islet development, with IGF-2 involved in islet cell proliferation and survival during the fetal and neonatal period and IGF-1 having a similar effect in childhood (25). Insulin synthesis and secretion occur primarily in response to post-prandial increases in blood glucose concentration, although amino acids such as leucine and arginine also stimulate insulin release. Glucose is transported into the $\beta$ cell by facilitated diffusion through the glucose transporter protein Slc2a2 (GLUT2) and phosphorylated by glucokinase, inducing oscillations in the ATP/ADP ratio. This alters plasma membrane permeability within the $\beta$ cell and insulin is secreted. Epigenetic change in any combination of these factors could, therefore, affect insulin action and glucose disposal. We found altered protein, mRNA and evidence of epigenetic change in several of these target genes. However, the main stimulus for this remains unclear. One possibility is a direct effect of pancreatic exposure to increased dietary protein via the portal circulation, given that protein intake has been shown to alter pancreatic development in rodent studies, and protein intake was increased by approximately $60 \%$ in the supplemented animals in our study.

We chose the first $2 \mathrm{wk}$ of life as the period of nutritional supplementation because previous studies have indicated that growth rate during this time is associated with later adverse health outcomes (26), and we anticipated that supplemented lambs would grow more rapidly. However, contrary to our expectation, the supplemented lambs in our study had decreased, rather than accelerated, growth during the period of supplementation. Provision of the supplement, which was given separately from ewe milk as all lambs were allowed to suckle freely from their ewe, did not, in fact, increase caloric intake compared with controls despite increasing protein intake. This is probably explained by the trend towards decreased voluntary intake of ewe milk, particularly in males. Taken together, these observations suggest that an altered dietary composition may be responsible for the observed changes in metabolic outcomes, as neither caloric intake nor growth were different between groups. This and other studies have shown that in the immediate postnatal period, nutritional intake and growth rate are not necessarily well correlated, particularly after intrauterine insult, so that growth rate cannot necessarily be assumed to be a valid proxy for nutritional intake (14). Relationships between accelerated neonatal growth and later metabolic disease may, therefore, reflect the presence of pre-existing metabolic derangement, rather than postnatal "overnutrition" per se, and the composition of postnatal diet, as well as caloric intake, may be additive to intrauterine insult in determining long-term outcomes.

One of the most striking findings of our study was the sexual dimorphism in both mRNA expression of key genes and insulin response to a glucose load. Sex-specific responses to early life environmental influences increasingly are being recognized in both humans and animals. Moreover, it has been demonstrated that the development of impaired glucose homeostasis in young adult rats exposed to maternal low protein diet during gestation and lactation involved different mechanisms in males and females $(27,28)$. While the female rat offspring were relatively more insulin deficient, with impaired glucose tolerance likely to be due to the reduction in the number and size of islets and $\beta$ cell mass, the male offspring were more insulin resistant, but with no difference in glucose tolerance compared to control animals despite basal insulin concentrations being twofold higher. In sheep, impaired glucose tolerance in offspring of ewes undernourished in the periconceptional period occurred earlier and was more pronounced in females (22), whereas fat mass in adulthood was increased only in male offspring (29). Human studies investigating long-term outcomes of nutritional enrichment after preterm birth or intrauterine growth restriction have also shown sexually dimorphic outcomes in neurodevelopment (30), weight gain (31), blood pressure (32), and adiposity (9) in infancy and childhood. However, there are fewer studies investigating alterations of diet in term babies. One study of term babies born small for gestational age found neurodevelopmental outcomes were worse in girls in the supplemented group at 9 mo of age, despite a positive effect on growth, although developmental differences between groups did not appear to persist at later follow up (30). The mechanisms underlying these dimorphic responses remain unclear.

The insulin response to glucose load was increased in supplemented males and decreased in supplemented females compared with same sex controls. In supplemented males, this resulted in a lower glucose $\mathrm{AUC}_{60}$, suggesting that the increased insulin secretion was due to intrinsic factors, rather than compensating for peripheral insulin resistance. However, the decreased AUC insulin in supplemented females was not associated with an increased glucose $\mathrm{AUC}_{60}$, which raises the possibility that peripheral insulin sensitivity might be increased. Although we specifically investigated the effect of nutritional supplements on pancreatic development and function, they may also have resulted in other sexually dimorphic effects on metabolism. 
Table 3. Composition of human breast milk, ewe milk, and fortifier

\begin{tabular}{|c|c|c|c|c|c|c|}
\hline & $\begin{array}{l}\text { Preterm human breast } \\
\text { milk per } 100 \mathrm{ml}\end{array}$ & $\begin{array}{l}\text { Breast milk } 100 \mathrm{ml}+ \\
\text { human milk fortifier }\end{array}$ & $\begin{array}{c}\% \text { increase with } \\
\text { human milk fortifier }\end{array}$ & $\begin{array}{l}\text { Ewe milk per } \\
100 \mathrm{ml}\end{array}$ & $\begin{array}{l}\text { Ewe milk } 100 \mathrm{ml}+ \\
\text { ewe milk fortifier }\end{array}$ & $\begin{array}{l}\% \text { increase with } \\
\text { ewe milk fortifier }\end{array}$ \\
\hline Energy (kcal) & 72 & 88 & 22 & 108 & 132 & 22 \\
\hline Fat (g) & 4.3 & 4.3 & 0 & 7.0 & 7.0 & 0 \\
\hline Carbohydrate (g) & 7.2 & 10.5 & 46 & 5.3 & 7.7 & 45 \\
\hline Vitamin C (mg) & 4.2 & 16.2 & 286 & 4.16 & 16.06 & 286 \\
\hline
\end{tabular}

The composition of ewe milk fortifier is based on the percentage increase of components provided with human breast milk fortifier. Breast milk composition taken from Foodworks (Version 5) 1998-2007, New Zealand (Xyris Software (Australia) Pty Ltd, Australia). Ewe milk composition information obtained from smallstock.info website (New Zealand).

The far right hand column represents the \% increase in composition of $100 \mathrm{ml}$ ewe's milk supplemented with the ewe milk fortifier.

We chose to look at epigenetic changes in the promotor region of the PDX1 gene because of its ubiquity in $\beta$ cell development and insulin production (33). Also, manipulation of the protein content in the postnatal diet in rodents has been found to alter both PDX1 expression and activation (34). The increased insulin mRNA expression that we found in supplemented female lambs is consistent with the decreased repressor marks and increased activator marks observed. However, as similar hypomethylation without altered insulin mRNA expression was observed in supplemented males, additional epigenetic modifications to those we examined are likely to have occurred. We examined both methylation and histone modifications in the PDX1 promoter but there may be other epigenetic mechanisms operating, such as epigenetic modifications in other loci that have downstream effects on the expression of PDX1, for example, through activity of microRNAs, that we have not examined. While the interactions between epigenetic change, mRNA expression and pancreatic function are clearly complex, it is likely that dietary composition, and in particular protein content, is a key moderator of pancreatic development. The differences in gene expression between sexes in the Control groups, the different relationships between epigenetic marks on PDX1 and gene expression between the sexes, and an interaction between sex and supplementation, all suggest that nutrition is a powerful environmental factor that affects the development of metabolic pathways differently in males and females.

\section{Limitations of the Study}

In this study, we standardized as far as possible confounding factors such as gestation length and ewe and lamb health. However, further information about the effect of the high protein, high calorie supplement on neonatal growth and metabolism could have been gained from measuring metabolic rate and body composition in the lambs. Estimates of ewe milk composition were taken from published data, but we did not measure composition directly in the ewes in our study. We also did not measure the non-nutritive components of ewe milk, to see if concentrations of hormones such as leptin and adipokines, which may have affected satiety in the lambs, were similar amongst groups. Milk intake was measured, but observation and recording of lamb feeding behaviour may have yielded additional information about timing and frequency of spontaneous feeds. Similarly, formal measurement of insulin sensitivity may have aided interpretation of the glucose tolerance tests. Longer-term studies looking at the duration of effect on the glucose-insulin axis beyond juvenile life will be important. Finally, it was beyond the scope of this study to measure the influence of nutritional supplements on the gut microbiome, but there is an increasing body of evidence suggesting that neonatal nutrition influences the composition of the microbiome, which in turn affects the development of metabolic pathways (35). Further studies of neonatal supplementation would be enriched by inclusion of outcome measures assessing effects on the gut microbiome.

\section{Implications for Practice}

In healthy term lambs, nutrition continues to influence pancreatic development via epigenetic change after birth in ways that affect later glucose-insulin axis function. We wished to determine the effect of supplementation in healthy, normally grown lambs as a first step to determine the effects of enhanced nutrition on the described outcomes independent of other variables. The experiment we describe does not compare a milk substitute with mother's milk and should not be extrapolated as such, but nutritional supplementation in addition to mother's milk that resulted in an altered dietary composition. Clearly, it would be of interest to investigate the impact of nutritional supplementation and dietary composition in other groups, such as growth restricted, preterm or twin lambs. While it is difficult to directly extrapolate these data to other species, it is likely that in humans also, nutritional manipulations in early postnatal life may alter later pancreatic function. This may be particularly relevant to infants born preterm or after nutritional insult, and requires further investigation. It is clear that neonatal dietary manipulation results in different physiological responses in males and females, so that for babies in whom neonatal nutritional supplementation is required, management plans may have to be sex specific.

Understanding how neonatal nutrition influences immediate and later pancreatic function, and further study into the reversibility of these effects, will contribute to the development of interventions to ameliorate adverse metabolic outcomes. 


\section{Articles | Jaquiery et al.}

Table 4. Primer and probe sequences for housekeeping genes

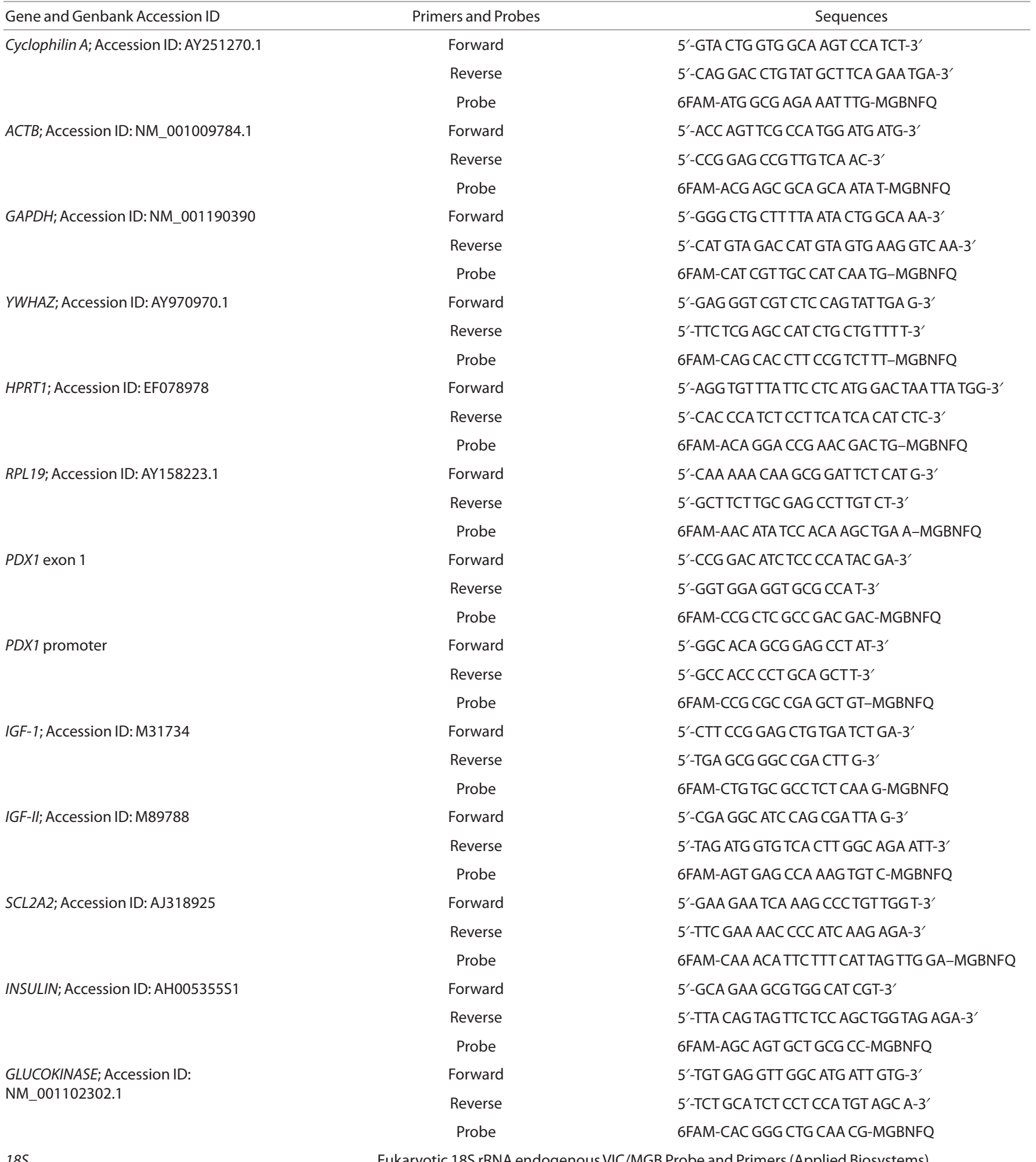

Eukaryotic 18S rRNA endogenous VIC/MGB Probe and Primers (Applied Biosystems).

FAMNIC, fluorescent reporter dyes bound to the TaqMan probe; MGBNFQ, molecular-groove binding non-fluorescence quencher. 
METHODS

All procedures used in this experiment were approved by the Animal Ethics Committee, University of Auckland (R628).

Singleton-bearing Romney ewes were identified by ultrasound scanning at $50 \mathrm{~d}$. One week before expected lambing (140 d of gestation (day 140); term = day 147), ewes were brought into the feedlot and housed in individual pens with open mesh sides, adjacent to other sheep. Prior to birth, lambs were randomized to either the supplemented group ( $\mathrm{S}$; allocated to receive a calorie dense nutritional supplement from days 1-14 after birth (day 0) in addition to suckling freely from their mother) or to the control group (C; allowed to suckle freely from their mother, and given aliquots of water in similar volume to the nutritional supplement). The supplement consisted of a mixture of protein (NZMP Whey Protein Isolate 895, Fonterra New Zealand) and carbohydrate (Maltodextrin Dextrose Equivalence of 18.0, Unitech Industries Limited, Auckland, New Zealand) powders plus vitamins A, C and D (KaricareVitadol C, Nutricia, Auckland, New Zealand) reconstituted in the minimal amount of water possible (approximately $20 \mathrm{ml}$ ). It was formulated to provide approximately $25 \%$ increase in daily calorie intake and $66 \%$ increase in daily protein intake, based on the additional intakes achieved clinically when milk fortifiers are added to expressed human breast milk, adjusted for ewe milk composition (Table 3). The total amount of supplement given was dependent on estimated milk intake based on postnatal day and weight of the lamb. Supplement for day 1 to day 3 was based on birth weight and an intake of $100 \mathrm{ml} \cdot \mathrm{kg}^{-1}$. day ${ }^{-1}$; increased to an intake of $120 \mathrm{ml} \cdot \mathrm{kg}^{-1} \cdot \mathrm{day}^{-1}$ (calculated on the day 4 weight) on days 4 to 7 and to $150 \mathrm{ml} \cdot \mathrm{kg}^{-1}$.day ${ }^{-1}$ (calculated on day 8 weight) from days 8 to 14. The supplement, or similar volume of water for the $C$ group, was administered via a syringe with a teat in two to four aliquots per day.

Milk intake was measured in a subset of lambs during the second week after birth using a deuterium oxide $\left(\mathrm{D}_{2} \mathrm{O}\right)$ dilutiontechnique (14).

Lambs were weighed at birth, on day 4 and day 8 and weekly thereafter until 12 wk of age. Growth velocity was calculated (36). At 2 wk after birth, lambs and ewes returned to the paddock and were brought in weekly for weighing. Weaning occurred at $12 \mathrm{wk}$ and lambs were separated from the ewes at this time and subsequently reared in sexsegregated flocks. All lambs remained intact.

At 4 mo of age, lambs were brought into the feedlot and weighed, and an IVGTT was performed. Jugular venous catheters were inserted using local anesthesia (xylocaine 2\%). Lambs were fasted overnight, but allowed free access to water. A baseline blood sample was taken and glucose bolus $(0.5 \mathrm{~g} / \mathrm{kg}$ of body weight of $50 \%$ glucose) was given intravenously at time 0 . Blood samples were taken at baseline, and at $2,5,10,15,20,30,40,50,60,80,100,120$, and 180 min post-glucose bolus, and the plasma frozen until analysis. Plasma glucose concentrations were measured by autoanalyser (Hitachi 902 Automatic Analyser; enzymatic colorimetric assay). Plasma ovine insulin concentration was measured by radioimmunoassay (RIA), using ovine insulin as the standard (Sigma Chemical, St Louis, MO). Glucose tolerance was calculated by plotting plasma glucose and insulin concentrations against time and calculating the area under the curve by a triangulation method, in the first hour of the test (glucose AUC and Insulin $\mathrm{AUC}_{60}$ ) to look for differences in first and second phase insulin release and for the whole duration of the test (glucose AUC and insulin $\mathrm{AUC}_{180}$ ).

After the IVGTT, a subset of lambs underwent postmortem examination. Organs were weighed and measured, and samples of liver and pancreas were collected.

The pancreas was bisected longitudinally, so that each half contained head, body, and tail. One half of the pancreas was rapidly frozen in liquid nitrogen and stored at $-80^{\circ} \mathrm{C}$ for further analysis.

\section{RNA Isolation and RT-PCR}

Whole pancreas was ground into powder in liquid nitrogen and well mixed in a container. Total RNA was extracted using TRIZOL (Invitrogen, Carlsbad, CA). RNA concentration was measured and the absorbance ratios $260 / 280$ and $260 / 230$ with ratios $\geq 1.9$ considered acceptable purity. RNA gels were run to check the RNA integrity. The band density ratios for $28 \mathrm{~S}$ rRNA and $18 \mathrm{~S}$ rRNA were determined using Image J software (National Institute of Health, Bethesda, MD) with ratios above 1.8 accepted as representing good quality intact RNA. Total RNA $(2.5 \mu \mathrm{g})$ was treated with RNase-free DNase I (Invitrogen) to eliminate potential genomic DNA. First-strand cDNA was synthesized using SuperScript VILO cDNA Synthesis system (Invitrogen, Life Technologies).

Primer Express Software (Applied Biosystems, Foster City, CA) was used to design Taqman probe and primer for real-time PCR (Table 2). A BLAST search ensured that primers and probes were not designed from homologous regions that would encode for genes other than the target genes.

\section{Real-Time PCR}

Real-time PCR was carried out using ABI 7900HT Real-Time PCR system (Applied Biosystems). Standard curves for the target and reference genes (Ref) were included in the runs to calculate the amplification efficiencies of the genes $(\mathrm{E}=10(-1 /$ slope $))$. Data were normalized to the geometric mean of the three most stably expressed reference genes. The relative expression ratios were calculated by a mathematical model (37):

$$
\text { Ratio }=(\text { Etarget })^{\Delta \text { Cttarget(control-sample) }} /(\text { Eref }) \Delta \text { Ctref(control-sample) }
$$

\section{Analysis of Stably Expressed Reference Genes}

We screened seven commonly used reference genes (GAPDH, BETA ACTIN, CLYCOPHILIN A, HPRT1, YWHAZ, 18S, RPL19) to select a panel of three genes for use as a composite reference. Reference gene expression levels were calculated based on a cycle threshold (Ct). The stability of the expression of the reference genes was evaluated by inspection of the SD and coefficient of variance (CV) calculated for each gene. The range of expression stability of the candidate reference genes based on the inspection of SD and CV was (from the most stable to the least stable): RPL19, GAPDH, HPRT1, YWHAZ, BETA ACTIN, CLYCOPHILIN, 18S. The Bestkeeper index (37) was calculated based on the geometric mean of the Ct values of the three most stably expressed reference genes, RPL19, GAPDH, and HPRT1, and was then used as a normalization factor in the analysis.

\section{Sequencing Ovine PDX1}

Due to the lack of sheep genomic sequence available, the bovine genome sequence which is highly homologous to the sheep (build Bos_taurus_UMD_3.1/bos Tau6) and porcine genome sequence (SGSC Sscrofa 9.2/susScr2) were used as a base to map PDX1 genes and its promoter region. Primers were designed against the conserved homologous regions and used to amplify ovine genomic DNA. The ovine PDX1 promoter region identified was located $209 \mathrm{bp}$ upstream of the transcriptional start site of the exon 1, and is CpG rich. Successfully amplified ovine genomic DNA from sequence -209 to +420 (GenBank accession number KP059125) was sent for sequencing and sequenced results were then aligned with bovine genome sequence using ClustalW 2.0 (European Molecular Biology Laboratory-European Bioinformatics Institute, Saffron Walden CB10 1SD, UK).

Primers used to sequence the ovine Pdx-1 were $5^{\prime}$-GGNCT GGCTTCTTAAGGC-3' and 5'-TATGGTTTAGTNCGACTCT-3'.

\section{Methylation Analysis of Pdx-1 Promoter}

Total genomic DNA was isolated from $100 \mathrm{mg}$ of pulverized pancreatic tissues. The MethylminerTM methylated DNA Enrichment kit (Invitrogen, Life Technologies, Carlsbad, CA) was used to separate methylated genomic DNA from total genomic DNA. Briefly, genomic DNA was digested using the MSE1 enzyme (New England Biolabs (NEB), Ipswich, MA) to give an average size of less than 1,000 bp. One microgram of digested DNA was used in each IP sample and $10 \%$ IP volume of digested DNA was used as Input DNA. The methylated DNA was captured from digested whole genomic DNA via binding the MethylMinerTM MBD-Biotin protein which coupled to Dynabeads M-280 Streptavidin. The methylated DNA was eluted from Dynabeads. Eluted methylated DNA was then cleaned and concentrated using Zymo Research ChIP DNA clean and concentrator kit (Zymo Research, Irvine, CA) before real time PCR analysis. Real time PCR was performed on Input DNA and compared with methylation-enriched DNA to establish relative differences in methylation 
state. Primers used in the real time PCR for methylation analysis were PDX1 promoter (Table 4 ), targeting from -179 to -81 base pairs relative to the transcriptional start site.

\section{Chromatin Immunoprecipitation (ChIP)}

Alterations of histones in the PDX1 promoter were measured using Active Motif ChIP-ITTM Express Enzymatic kit (Active Motif, Australian Bioresearch, WA, Australia). Briefly, $140 \mathrm{mg}$ of pulverized pancreatic tissues were fixed in $1 \%$ formaldehyde for $5 \mathrm{~min}$. Sonication was performed to yield DNA fragments ranging in size from $200-1,500 \mathrm{bp}$. Thirty-eight micrograms of sheared chromatin were used in immunoprecipitation (IP) and $1 \%$ of IP volume was used as input DNA. IP was carried out overnight with either $3 \mu \mathrm{g}$ of Histone $\mathrm{H} 3$ acetyl Lys9 pAb (Active Motif), Histone H3 trimethyl Lys27 pAb (Active Motif), Histone H3 trimethyl Lys4 (Active Motif), RNA pol II mAb (Active Motif), or normal rabbit IgG (Cell Signalling). RNase POL II was used as a positive control and rabbit IgG was used as a negative control. The resulting enriched DNA and the Input DNA were cleaned and concentrated using Zymo Research ChIP DNA clean and concentrator kit (Zymo Research) before real time PCR analysis. Real-time PCR was performed on input DNA as described above and compared with IP enriched DNA to establish relative differences in histone modifications. Primer used in real-time PCR for CHiP analysis was PDX1 promoter (Table 4). IP data were normalized to both its input DNA and negative control.

\section{Statistics}

Data are presented as mean \pm SEM.

Differences in growth and glucose tolerance between control and supplement groups were analyzed using ANOVA, with Fisher post hoc test.

Data for real-time PCR and epigenetic studies are presented as relative expression ratios of the male and female $\mathrm{S}$ groups relative to the same sex C group with 95\% confidence intervals (CI).

\section{ACKNOWLEDGMENTS}

Thanks to Jacob Bae, the staff of Ngapouri Research Farm, Liggins Institute, University of Auckland; Eric Thorstensen and other laboratory staff at the Liggins Institute, University of Auckland and Barbara Cormack, Auckland City Hospital, New Zealand.

\section{STATEMENT OF FINANCIAL SUPPORT}

This study was supported by Health Research Council of New Zealand and Gravida, Centre for Growth and Development, New Zealand.

Disclosure: There is no conflict of interest to declare

\section{REFERENCES}

1. Harding JE. The nutritional basis of the fetal origins of adult disease. Int $J$ Epidemiol 2001;30:15-23.

2. O'Dowd JF, Stocker CJ. Endocrine pancreatic development: impact of obesity and diet. Front Physiol 2013;4:170.

3. Bréant $\mathrm{B}, \mathrm{Gesina} \mathrm{E}, \mathrm{Blondeau} \mathrm{B}$. Nutrition, glucocorticoids and pancreas development. Horm Res 2006;65 Suppl 3:98-104.

4. Petrik J, Srinivasan M, Aalinkeel R, et al. A long-term high-carbohydrate diet causes an altered ontogeny of pancreatic islets of Langerhans in the neonatal rat. Pediatr Res 2001;49:84-92.

5. Hester SN, Hustead DS, Mackey AD, Singhal A, Marriage BJ. Is the macronutrient intake of formula-fed infants greater than breast-fed infants in early infancy? J Nutr Metab 2012;2012:891201.

6. Cormack BE, Bloomfield FH. Audit of feeding practices in babies $<1200 \mathrm{~g}$ or 30 weeks gestation during the first month of life. J Paediatr Child Health 2006;42:458-63.

7. Lucas A, Fewtrell MS, Morley R, et al. Randomized trial of nutrientenriched formula versus standard formula for postdischarge preterm infants. Pediatrics 2001;108:703-11.

8. Lucas A, Morley R, Cole TJ, et al. Early diet in preterm babies and developmental status at 18 months. Lancet 1990;335:1477-81.
9. Singhal A, Kennedy K, Lanigan J, et al. Nutrition in infancy and long-term risk of obesity: evidence from 2 randomized controlled trials. Am J Clin Nutr 2010;92:1133-44.

10. Singhal A, Fewtrell M, Cole TJ, Lucas A. Low nutrient intake and early growth for later insulin resistance in adolescents born preterm. Lancet 2003;361:1089-97.

11. Manco M, Alterio A, Bugianesi E, et al. Insulin dynamics of breast- or formula-fed overweight and obese children. J Am Coll Nutr 2011;30:29-38.

12. Cianfarani S, Geremia C, Germani D, Scirè G, Maiorana A, Boemi S. Insulin resistance and insulin-like growth factors in children with intrauterine growth retardation. Is catch-up growth a risk factor? Horm Res 2001;55 Suppl 1:7-10.

13. Jackson AA. Nutrients, growth, and the development of programmed metabolic function. Adv Exp Med Biol 2000;478:41-55.

14. Jaquiery AL, Oliver $\mathrm{MH}$, Bloomfield FH, Harding JE. Periconceptional events perturb postnatal growth regulation in sheep. Pediatr Res 2011;70:261-6.

15. Delghingaro-Augusto V, Ferreira F, Bordin S, et al. A low protein diet alters gene expression in rat pancreatic islets. J Nutr 2004;134:321-7.

16. Waterland RA, Garza C. Early postnatal nutrition determines adult pancreatic glucose-responsive insulin secretion and islet gene expression in rats. J Nutr 2002;132:357-64.

17. Green AS, Rozance PJ, Limesand SW. Consequences of a compromised intrauterine environment on islet function. J Endocrinol 2010;205:211-24.

18. Yuan Q, Chen L, Liu C, Xu K, Mao X, Liu C. Postnatal pancreatic islet $\beta$ cell function and insulin sensitivity at different stages of lifetime in rats born with intrauterine growth retardation. PLoS One 2011;6:e25167.

19. Dumortier O, Blondeau B, Duvillié B, Reusens B, Bréant B, Remacle C. Different mechanisms operating during different critical time-windows reduce rat fetal beta cell mass due to a maternal low-protein or low-energy diet. Diabetologia 2007;50:2495-503.

20. Gatford KL, Mohammad SN, Harland ML, et al. Impaired beta-cell function and inadequate compensatory increases in beta-cell mass after intrauterine growth restriction in sheep. Endocrinology 2008;149:5118-27.

21. Limesand SW, Rozance PJ, Macko AR, Anderson MJ, Kelly AC, Hay WW Jr. Reductions in insulin concentrations and $\beta$-cell mass precede growth restriction in sheep fetuses with placental insufficiency. Am J Physiol Endocrinol Metab 2013;304:E516-23.

22. Todd SE, Oliver MH, Jaquiery AL, Bloomfield FH, Harding JE. Periconceptional undernutrition of ewes impairs glucose tolerance in their adult offspring. Pediatr Res 2009;65:409-13.

23. Srinivasan M, Laychock SG, Hill DJ, Patel MS. Neonatal nutrition: metabolic programming of pancreatic islets and obesity. Exp Biol Med (Maywood) 2003;228:15-23.

24. Stoffers DA, Thomas MK, Habener JF. Homeodomain protein IDX-1: a master regulator of pancreas development and insulin gene expression. Trends Endocrinol Metab 1997;8:145-51.

25. Hill DJ, Duvillié B. Pancreatic development and adult diabetes. Pediatr Res 2000;48:269-74.

26. Singhal A, Cole TJ, Fewtrell M, Deanfield J, Lucas A. Is slower early growth beneficial for long-term cardiovascular health? Circulation 2004;109:110813 .

27. Sugden MC, Holness MJ. Gender-specific programming of insulin secretion and action. J Endocrinol 2002;175:757-67.

28. Chamson-Reig A, Thyssen SM, Hill DJ, Arany E. Exposure of the pregnant rat to low protein diet causes impaired glucose homeostasis in the young adult offspring by different mechanisms in males and females. Exp Biol Med (Maywood) 2009;234:1425-36.

29. Jaquiery AL, Oliver MH, Honeyfield-Ross M, Harding JE, Bloomfield FH. Periconceptional undernutrition in sheep affects adult phenotype only in males. J Nutr Metab 2012;2012:123610.

30. Morley R, Fewtrell MS, Abbott RA, Stephenson T, MacFadyen U, Lucas A. Neurodevelopment in children born small for gestational age: a randomized trial of nutrient-enriched versus standard formula and comparison with a reference breastfed group. Pediatrics 2004;113(3 Pt 1):515-21. 
31. Fewtrell MS, Morley R, Abbott RA, et al. Catch-up growth in small-for-gestational-age term infants: a randomized trial. Am J Clin Nutr 2001;74:516-23.

32. Parkinson JR, Hyde MJ, Gale C, Santhakumaran S, Modi N. Preterm birth and the metabolic syndrome in adult life: a systematic review and metaanalysis. Pediatrics 2013;131:e1240-63.

33. Park JH, Stoffers DA, Nicholls RD, Simmons RA. Development of type 2 diabetes following intrauterine growth retardation in rats is associated with progressive epigenetic silencing of Pdx1. J Clin Invest 2008;118:2316-24.

34. Abuzgaia AM, Hardy DB, Arany E. Regulation of postnatal pancreatic $\mathrm{Pdx} 1$ and downstream target genes after gestational exposure to protein restriction in rats. Reproduction 2015;149:293-303.
35. Nauta AJ, Ben Amor K, Knol J, Garssen J, van der Beek EM. Relevance of pre- and postnatal nutrition to development and interplay between the microbiota and metabolic and immune systems. Am J Clin Nutr 2013;98:586S-93S.

36. Patel AL, Engstrom JL, Meier PP, Kimura RE. Accuracy of methods for calculating postnatal growth velocity for extremely low birth weight infants. Pediatrics 2005;116:1466-73.

37. Pfaffl MW, Tichopad A, Prgomet C, Neuvians TP. Determination of stable housekeeping genes, differentially regulated target genes and sample integrity: BestKeeper-Excel-based tool using pair-wise correlations. Biotechnol Lett 2004;26:509-15. 